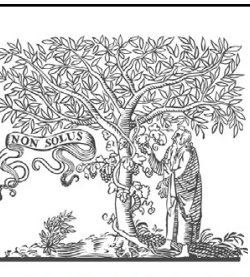

\title{
Microbiology and outcomes of community acquired pneumonia in non cystic-fibrosis bronchiectasis patients
}

\author{
Eva Polverino ${ }^{a}$, Catia Cilloniz ${ }^{a}$, Rosario Menendez ${ }^{b}$, \\ Albert Gabarrus ${ }^{a}$, Edmundo Rosales-Mayor ${ }^{a}$, Victoria Alcaraz ${ }^{a}$, \\ Silvia Terraneo ${ }^{c}$, Jordi Puig de la Bella Casa ${ }^{d}$, Josep Mensa ${ }^{e}$, \\ Miquel Ferrer ${ }^{a}$, Antoni Torres ${ }^{\mathrm{a}, *}$
}

\footnotetext{
a Department of Pneumology, Institut Clinic del Tórax, Hospital Clinic of Barcelona - Institut d'Investigacions Biomèdiques August Pi i Sunyer (IDIBAPS), University of Barcelona, Ciber de Enfermedades Respiratorias (CIBERES), Spain

${ }^{\mathrm{b}}$ Department of Pneumology, Hospital La Fe Valencia, Ciber de Enfermedades Respiratorias (CIBERES), Spain

'Respiratory Unit, San Paolo Hospital, Dipartimento di Scienze della Salute, Università degli Studi di Milano, Milan, Italy

${ }^{\mathrm{d}}$ Department of Microbiology, Hospital Clinic of Barcelona, Spain

e Department of Infectious Disease, Hospital Clinic of Barcelona, Spain
}

Accepted 28 March 2015

Available online

\section{KEYWORDS}

Community-acquired pneumonia;

Non-cystic fibrosis bronchiectasis;

Etiology
Summary Background: It is general belief that Non-cystic fibrosis bronchiectasis (NCFB) is characterized by frequent community-acquired pneumonia. Nonetheless, the knowledge on clinical characteristics of CAP in NCFBE is poor and no specific recommendations are available. We aim to investigate clinical and microbiological characteristics of NCFBE patients with CAP. Methods: Prospective observational study of 3495 CAP patients (2000-2011).

Results: We found $90(2.0 \%)$ NCFBE-CAP that in comparison with non-bronchiectatic CAP (n, 3405 ) showed older age (mean \pm [SD], NCFBE-CAP $73 \pm 14$ vs. CAP $65 \pm 19 y r s$ ), more vaccinations (pneumococcal: $35 \%$ vs. $14 \%$; influenza: $60 \%$ vs. $42 \%$ ), comorbidities ( $n \geq 2: 43 \%$ vs. $25 \%$ ), previous antibiotics ( $38 \%$ vs. $22 \%$ ), and inhaled steroids (53\% vs. $16 \%$ ) ( $p<0.05$ each). Streptococcus pneumoniae was the most frequent isolate in both groups (NCFBE-CAP $44.4 \%$ vs. CAP $42.7 \% ; p=0.821$ ) followed by respiratory virus, mixed infections and atypical bacteria. Considering overall frequencies of the main pathogens (including monomicrobial and mixed infections) Pseudomonas aeruginosa $(15.5 \%$ vs. $2.9 \%$; $p<0.001)$ and Enterobacteriaceae $(8.8 \%$

\footnotetext{
* Corresponding author. Department of Pneumology, Hospital Clinic, Villarroel 170, Barcelona, Spain. Tel.: +34 932275549.

E-mail address: atorres@clinic.ub.es (A. Torres).
} 
vs. $2.4 \% ; p=0.025)$ were more prevalent in NCFBE-CAP patients than in CAP.

Despite these clinical and microbiological differences, NCFBE-CAP showed similar outcomes to CAP patients (mortality, length of hospital stay, etc.).

Conclusions: NCFBE-CAP patients are usually older and have more comorbidities but similar outcomes than general CAP population. Usual CAP pathogens, such as S. pneumoniae, are also involved in NCFBE-CAP but $P$. aeruginosa and other Enterobacteriaceae were globally more frequent than in CAP. Therefore, a wide microbiological investigation should be recommended in all NCFBE-CAP cases as well as routine pneumococcal vaccination for prevention of pneumonia.

(c) 2015 The British Infection Association. Published by Elsevier Ltd. All rights reserved.

\section{Introduction}

Non-cystic fibrosis bronchiectasis (NCFBE) is defined by the presence of abnormal and irreversible bronchial widening secondary to a non-CF cause and is usually characterized by ${ }^{1}$ chronic inflammatory disease, ${ }^{2}$ frequent respiratory infections, including pneumonia ${ }^{1-3}$ progressive loss of lung function, ${ }^{4}$ worsening in quality of life and ${ }^{5}$ a considerable economic burden over time. ${ }^{3,4}$

Few data are available about incidence of NCFBE, but in the USA an overall prevalence of 52 per 100000 has been reported. $^{5}$

Severe or recurrent pneumonia is considered a potential cause of bronchiectasis but also the initial clinical manifestation of NCFBE despite poor scientific evidence. ${ }^{6-8}$ Nevertheless, the scientific literature on the prevalence of pneumonia among NCFBE patients is limited. ${ }^{6,7,9}$ Moreover, the diagnosis of NCFBE is frequently achieved with a considerable delay due to the need of an HRCT scan and many patients may suffer different episodes of pulmonary infection and a progression in lung damage before the diagnosis is confirmed. Therefore, the presence of bronchiectasis is usually considered a risk condition for communityacquired pneumonia (CAP) although this association has been clearly demonstrated only for bronchiectasis secondary to primary antibody deficiencies. ${ }^{10}$

In addition, as almost $40-60 \%$ of NCFBE patients suffer chronic airway infection by potential multidrug resistant (MDR) pathogens, ${ }^{6,11,12}$ NCFBE patients are considered at risk of Pseudomonas aeruginosa and current CAP guidelines consider NCFBE a risk factor for treatment failure due to inadequate antibiotic coverage. ${ }^{13,14}$ Unfortunately, the information on the etiology and outcomes of pneumonia in NCFBE is extremely scarce nowadays and no specific clinical recommendations are currently available.

We aimed to investigate clinical characterization, microbial etiology and outcomes of CAP in NCFBE patients in comparison with non-bronchiectatic patients with the objective to clarify clinical recommendations to treat CAP in NCFBE patients.

\section{Materials and methods}

\section{Study population}

We prospectively studied 4413 consecutive cases of adults patients admitted to the emergency department with suspicion of CAP from 2000 to 2011 in an 850-bed tertiary care university hospital in Barcelona, Spain. Among these, we investigated patients with an established or new diagnosis of NCFBE confirmed by HRCT. The exclusion criteria were: a) severe immunosuppression, such as in solid-organ or bone-marrow transplantation or AIDS, or receiving chemotherapy or other immunosuppressive drugs ( $>20 \mathrm{mg}$ prednisone-equivalent per day for $\geq 2$ weeks); b) hospitalization in the preceding 21 days; c) active tuberculosis; d) Health care-associated pneumonia (HCAP) excepting nursing home (although HCAP criteria were defined in 2005, they had been individually set as exclusion criteria for our (AP database since 1996), e) cystic fibrosis and $f$ ) cases with confirmed alternative diagnosis at the end of follow-up. Cystic fibrosis was systematically ruled out in all bronchiectatic patients in the study (sweat test and genetic screening according to European guidelines). ${ }^{15}$

\section{Definitions}

CAP and other definitions are described in the online supplemental material. Concordant opinions were required by two independent reviewers (the attending physician and a medical researcher external to data analysis) of chest x-rays and CT scans, when available, to confirm diagnosis of pneumonia and exclude "simple exacerbations of NCFBE or any other chronic respiratory disease (COPD, etc.)".

NCFBE was defined clinically and radiologically and not related to $\mathrm{CF}$, and was confirmed by high-resolution computerized tomography (HRCT). CT scan had been performed before CAP episode or during hospital admission or CAP follow-up by the attending physician for two main reasons: late response to treatment or diagnostic screening due to clinical and/or radiological suspicion (chest X-rays) of bronchiectasis and/or other subsistent respiratory disease. Chronic bronchial infection was defined as at least 2 respiratory isolates of the same pathogen in the last year ( 3 months apart) before pneumonia. ${ }^{16}$

\section{Data collection and follow-up}

Data collection during hospital admission (including demographics, comorbidities, previous vaccinations and antimicrobial therapy, signs and symptoms of clinical presentation, complete and systematic microbiological 
investigations, antimicrobial therapy and steroids) and follow-up is widely described in the online supplemental material. ${ }^{17}$ All surviving patients were re-examined or at least telephonically contacted 4-6 weeks after discharge from the emergency care unit in the outpatients' clinic in order to assess clinical resolution (30-day mortality rate). PSI and CURB-65 classes were assigned according to the original authors' designations.

Antibiotic therapy was recorded in all cases and its adequacy to current Spanish guidelines for $\mathrm{CAP}^{18}$ treatment was evaluated such as its appropriateness ${ }^{19,20}$ according to microbiological findings in those patients with a known microbial etiology of pneumonia.

The prospective collection of clinical data was approved by the Institutional Review Board. Patients' identification remained anonymous and informed consent was considered unnecessary due to the observational nature of the study. All reported data are the result of the clinical routine activity and all tests and procedures were ordered by the attending physicians, not involved in this study.

\section{Statistical analysis}

We performed a secondary analysis of a prospectively analysis collected CAP database in order to investigate NCFBE subgroup. We show $n$ (\%) for categorical variables and median (IQR) for continuous variables with nonnormal distribution or mean \pm SD for those with normal distribution. Categorical variables were compared with the chi-square test or Fisher's exact test. Continuous variables were compared using the Student's t-test or the nonparametric Mann-Whitney $U$ test. Univariate and multivariate logistic regression analyses were performed to identify variables available at presentation in the emergency room of our Hospital that predicted hospitalization, ICU admission (dependent variable, see online supplemental material) 30-day mortality and prolonged length of stay (LOS $>7$ days; cut-off value the median value of LOS).

Univariate and multivariate logistic regression analyses were performed to identify variables predictive of patients' hospitalization, ICU admission, 30-day mortality and prolonged LOS (dependent variables). The variables analyzed univariately were: age ( $<65$ vs. $\geq 65$ years), gender, smoking, influenza vaccination, pneumococcal vaccination, inhaled corticosteroids, previous antibiotic, bronchiectasis, COPD, chronic cardiovascular disease, diabetes mellitus, neurological disease, chronic renal disease, chronic liver disease, cough, sputum, dyspnoea, chest pain, fever, altered mental status, PSI class (I-III vs. IV-V), CURB-65 (12 vs. $3-5)$, serum creatinine ( $<1.5$ vs. $\geq 1.5 \mathrm{mg} / \mathrm{dL}$ ), C-RP $(<18$ vs. $\geq 18 \mathrm{mg} / \mathrm{dL}$ [median]), WBC count $(<4$ vs. $\geq 4 \times 10^{9}$ cell/L), platelets count $(<100$ vs. $\geq 100 \times 10^{9}$ cell $\left./ L\right)$, respiration rate ( $<30$ vs. $\geq 30$ breaths per min.), systolic blood pressure (<90 vs. $\geq 90 \mathrm{mmHg}$ ), temperature $\left(<36\right.$ vs. $\left.\geq 36{ }^{\circ} \mathrm{C}\right)$, SatO $_{2} \quad(<92$ vs. $\geq 92 \%)$, $\mathrm{PaO}_{2} / \mathrm{FiO}_{2}(<250$ vs. $\geq 250)$, pleural effusion, multilobar infiltration, ARDS, acute renal failure, etiology, and bacteraemia.

Variables that showed a significant result univariately $(p<0.1)$ were included in the corresponding multivariate logistic regression backward stepwise model. Variables highly correlated were excluded from multivariate analyses. The Hosmer-Lemeshow goodness-of-fit test was performed to assess the overall fit of the model ${ }^{21}$. All tests were two-tailed and significance was set at 5\%. All analyses were performed with IBM SPSS Statistics 18.0 (Armonk, New York, USA).

\section{Results}

\section{General characteristics of the study population}

After excluding patients with immunodepression and nosocomial pneumonia (previous hospitalization in the last 3 months) we analyzed 3731 CAP and NCFBE were described in 124 patients but they were confirmed by HRCT only in 111 cases (3.0\%) (Fig. 1). Overall, 188 patients had more than one episode of CAP during the study period (162 patients with 2 episodes of pneumonia, 26 with 3 episodes) but only first episode was considered for the final analysis. It is worth noting that NCFBE patients had significantly more recurrent pneumonia (mean rate of CAP 1.23; $n$ of recurrent CAP, 21 [18.9\%]) than non-bronchiectatic patients (mean rate $1.059 ; \mathrm{n}$ of recurrent CAP, 202 [5.6\%]) $(p<0.001)$. We finally analyzed 3495 patients including 3405 CAP and 90 NCFBE-CAP patients.

A total of 52 (58\%) NCBE-CAP patients had an NCFBE diagnosis prior to pneumonia, whereas 38 (42\%) patients were diagnosed during the current CAP episode by HRCT scan showing diffuse multilobar bronchiectasis also affecting lobes not involved in pneumonia, that were considered, therefore, pre-existing to pneumonia. Data of clinical history, clinical presentation and outcomes from patients diagnosed of NCFBE before and during CAP were compared, showing no significant differences between the 2 groups (on-line supplement Table $1 \mathrm{~b}$ ).

To further confirm the homogeneity of NCFBE patients (diagnosed before or during CAP) we exclusively compared NCFBE patients diagnosed before pneumonia $(n, 52)$ with CAP group (on-line supplement Table $1 \mathrm{~b}$ ) and found no differences from the overall analysis including all NCFBE patients (Tables 1 and 2).

Globally, the underlying etiologies of bronchiectasis were: idiopathic 27 (30\%), previous tuberculosis 28 (31\%), other post-infectious causes $8(9 \%)$, primary immunological abnormalities 5 (6\%), COPD $17(19 \%)$, asthma 3 (3\%), ciliary dyskinesia $1(1 \%)$, Mounier-Kuhn syndrome $1(1 \%)$.

\section{Comparison of CAP and CAP-NCFBE patients}

The differences in baseline characteristics between patients with CAP and those with CAP and NCFBE are summarized in Table 1. The NCFBE group showed older age and more females, higher rates of vaccinations, more comorbidities and previous treatment with inhaled (ICs), oral corticosteroids and antibiotics in the last month. Moreover, NCFBE patients presented more expectoration, dyspnoea, and leukocytosis and needed more hospitalization but showed similar PSI and CURB-65 scores (Tables 1 and 2). 


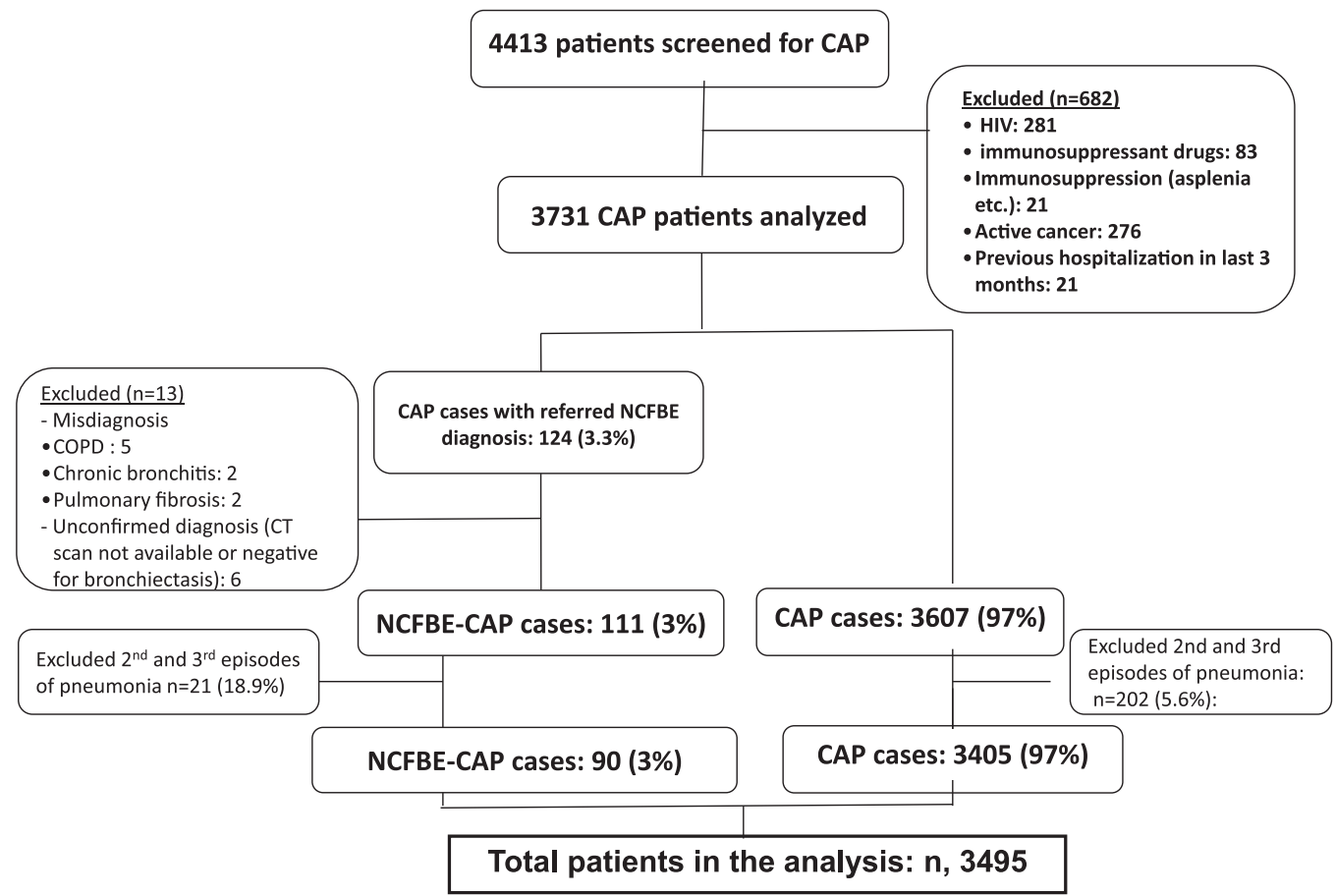

Figure 1 Flow diagram of the selected population. Abbreviations: NCFBE, non-cystic fibrosis bronchiectasis; CAP, communityacquired pneumonia; COPD, chronic obstructive pulmonary disease; CT, computed tomography.

\section{Microbial etiology}

Microbiological diagnosis was achieved in $41.1 \%$ of CAP patients $(n, 1399)$ and in $50.0 \%(n, 45)$ of NCFBE-CAP subgroup ( $p=0.091)$.

Streptococcus pneumoniae was largely the most prevalent causative pathogen of CAP in both groups, followed by respiratory virus, mixed infections and atypical bacteria (Table 3). Among cases of polymicrobial infection $P$. aeruginosa (plus other) was more frequent in NCFBE-CAP (13.3\%) than in CAP $(1.0 \%$; $p<0.01)$, while other combinations (with S. pneumoniae [8.9\% vs. 8.3], Haemophilus influenzae $[4.4 \%$ vs. $2.9 \%]$, etc.) were similarly distributed between the two groups.

Table 4 shows the overall prevalence rates of main pathogens as isolated alone (monomicrobial pneumonia) and/or in combination with any other pathogen (mixed infection), $P$. aeruginosa and Enterobacteriaceae being more frequent among NCFBE-CAP than in CAP.

Only 10 NCFBE patients $(11.1 \%)$ had a known chronic bronchial infection prior to the pneumonia episode $(6$ cases of $P$. aeruginosa, 2 of MSSA; 1 of Escherichia coli, $1 \mathrm{H}$. influenzae): in 3 of them the "chronic" microorganism coincided with etiology of pneumonia and in 4 cases the "chronic" microorganism was isolated in CAP as well, but in association with a new pathogen; globally 7 of 10 cases of chronic bronchial infection showed the same pathogen during CAP.

\section{Antibiotic treatment}

Data on antibiotic treatment were available in 3462 (99\%) patients. The most frequent regimens were beta-lactam plus macrolide ( $\mathrm{n}=1188,34.3 \%$ ), fluoroquinolone monotherapy ( $\mathrm{n}=916,26.5 \%$ ), fluoroquinolones plus betalactam ( $\mathrm{n}=758,21.9 \%$ ). These regimens were similarly administered in patients with and without NCFBE (all, $p>0.05)$.

Antibiotic therapy was adequate (according to current Spanish guidelines for CAP treatment ${ }^{18}$ ) in most cases but less frequently in NCFBE-CAP than in CAP (NCFBE-CAP, $77.8 \%$ vs. CAP, $89.0 \%$ of cases; $p=0.020$ ), mostly because of the administration of a combination of a beta-lactam plus a glycopeptide or an aminoglycoside (covering possible MDR infections). However, the antibiotic therapy was also appropriate in relation with microbial etiology in most cases of CAP (93.8\%, $n=1069)$ and NCFBE-CAP $(87.8 \%$, $\mathrm{n}=36 ; \mathrm{p}=0.126)$.

Among cases of $P$. aeruginosa infection, there was a rate of appropriate therapy (according to microbial etiology) of $43 \%$ ( 3 out of 7 cases) in NCFBE-CAP and 33\% (13 out of 40 cases) in the CAP group ( $p=0.680)$; this mild and non significant difference was due to the increased trend to cover potential MDR pathogens among NCFBE patients, compared to CAP.

\section{Outcomes and prognostic factors}

A non significant trend to increased hospitalization (particularly ICU) was observed in the NCFBE-CAP group, but no differences were observed in mortality and/or any other severity marker such as MV, LOS, pulmonary and systemic complications of pneumonia between the two groups (Table 2), despite significant differences in age and number of comorbidities. 
Table 1 Characteristics of patients with and without Non-CF Bronchiectasis $(n=3495)$.

\begin{tabular}{|c|c|c|c|}
\hline Variable & NCFBE-CAP $(n=90)$ & CAP $(n=3405)$ & $p$-Value ${ }^{a}$ \\
\hline \multicolumn{4}{|l|}{ Demographic } \\
\hline Age (years), mean \pm SD & $73 \pm 14$ & $65 \pm 19$ & 0.001 \\
\hline Age $\geq 65$ years, $n(\%)$ & $73(81)$ & $1996(58.6)$ & $<0.001$ \\
\hline Sex (male), n (\%) & $31(34.4)$ & $22,087(61.3)$ & $<0.001$ \\
\hline Smoking, $\mathrm{n}(\%)$ & & & $<0.001$ \\
\hline No smoker & $56(62.2)$ & $1512(44.8)$ & \\
\hline Current smoker & $6(6.7 \%)$ & $860(25.5)$ & \\
\hline Ex-smoker & $28(31.1)$ & $1005(29.8)$ & \\
\hline Alcohol, n (\%) & & & 0.133 \\
\hline No alcohol consumer & $80(89.9)$ & $2732(81.6)$ & \\
\hline Current alcohol consumer & $9(8.2)$ & $495(14.8)$ & \\
\hline Ex-alcohol consumer & $35(2.7)$ & $122(3.6)$ & \\
\hline Previous antibiotic, n (\%) & $32(37.6)$ & $711(21.8)$ & $<0.001$ \\
\hline Nursing home residence, $\mathrm{n}(\%)$ & $3(3.3 \%)$ & $82(2.4)$ & 0.584 \\
\hline Influenza vaccine, n (\%) & $42(60.0)$ & $1167(41.5)$ & $<0.001$ \\
\hline Pneumococcal vaccine, n (\%) & $24(34.8)$ & $397(14.2)$ & $<0.001$ \\
\hline Inhaled corticosteroid, n (\%) & $47(52.8)$ & $525(15.6)$ & $<0.001$ \\
\hline Systemic corticosteroid, n (\%) & $4(5.1)$ & $47(1.5)$ & 0.012 \\
\hline Number of comorbidities $\geq 2, n$ (\%) & $39(43.3)$ & $847(24.9)$ & $<0.001$ \\
\hline Chronic cardiovascular disease & $17(18.9)$ & $586(17.3)$ & 0.693 \\
\hline Diabetes mellitus & $10(11.5)$ & $544(16.5)$ & 0.210 \\
\hline Neurological disease & $13(14.4)$ & $596(17.7)$ & 0.428 \\
\hline Chronic renal disease & $6(6.7)$ & $209(6.2)$ & 0.847 \\
\hline Haemodialysis & $0(0)$ & $7(0.2 \%)$ & 1.000 \\
\hline Chronic liver disease & $6(6.7)$ & $147(4.3)$ & 0.288 \\
\hline COPD & $17(19.0)$ & 507 (14.9) & 0.373 \\
\hline \multicolumn{4}{|l|}{ Clinical findings, n (\%) } \\
\hline Cough & $76(84.4)$ & $2748(79.7)$ & 0.259 \\
\hline Sputum & $66(75.0)$ & 1877 (56.9) & $<0.001$ \\
\hline Dyspnoea & $70(78.8)$ & $2188(65.3)$ & 0.009 \\
\hline Chest pain & $38(42.2)$ & $1396(41.8)$ & 0.937 \\
\hline Fever & $76(87.4)$ & $2684(82.73)$ & 0.252 \\
\hline Altered mental status & $13(14.4)$ & $608(18.0)$ & 0.389 \\
\hline \multicolumn{4}{|l|}{ Vital signs } \\
\hline Respiration rate (breaths per min.), median (IQR) & $24.5(20.0-32.0)$ & $24.0(20.0-30.0)$ & 0.276 \\
\hline Respiration rate $\geq 30$ breaths per min., $\mathrm{n}(\%)$ & $25(29.8)$ & $878(28.2)$ & 0.754 \\
\hline Temperature $\left({ }^{\circ} \mathrm{C}\right)$, median $(\mathrm{IQR})$ & $37.6(36.6-38.2)$ & $37.6(36.6-38.3)$ & 0.307 \\
\hline Temperature $<36{ }^{\circ} \mathrm{C}, \mathrm{n}(\%)$ & $4(4.9)$ & $185(5.9)$ & 0.673 \\
\hline Systolic blood pressure (mmHg), median (IQR) & $139.5(116.5-154.0)$ & $130.0(114.0-149.0)$ & 0.051 \\
\hline Systolic blood pressure $<90$ mmHg, n (\%) & $1(1.1)$ & $129(3.9)$ & 0.108 \\
\hline \multicolumn{4}{|l|}{ Laboratory findings } \\
\hline Creatinine $(\mathrm{mg} / \mathrm{dL})$, median $(\mathrm{IQR})$ & $1.0(0.8-1.2)$ & $1.0(0.9-1.4)$ & 0.059 \\
\hline C-reactive protein level $(\mathrm{mg} / \mathrm{dL})$, median (IQR) & $16.0(5.0-23.7)$ & $17.7(8.9-27.1)$ & 0.074 \\
\hline C-reactive protein level $\geq 18 \mathrm{mg} / \mathrm{dL}, \mathrm{n}(\%)$ & $33(45.2)$ & $1349(49.4)$ & 0.482 \\
\hline WBC count $\left(\times 10^{9}\right.$ cell/L), median (IQR) & $14.7(9.9-19.7)$ & $12.6(8.9-17.3)$ & 0.017 \\
\hline Leukopenia $\left(<4 \times 10^{9} \mathrm{WBC} / \mathrm{L}\right), \mathrm{n}(\%)$ & $0(0)$ & $96(2.9)$ & 0.104 \\
\hline Platelets count $\left(\times 10^{9}\right.$ cell $\left./ L\right)$, median (IQR) & $260.0(175.0-346.0)$ & $237.0(184.0-302.0)$ & 0.250 \\
\hline Thrombocytopenia (<100 × $10^{9}$ cell/L), n (\%) & $0(0)$ & $54(2.7)$ & 0.212 \\
\hline $\mathrm{SatO}_{2}<92 \%$ in room air, $\mathrm{n}(\%)$ & $21(40.4)$ & $655(33.5)$ & 0.522 \\
\hline $\mathrm{PaO}_{2} / \mathrm{FIO}_{2}$, median (IQR) & $273.0(238.1-309.5)$ & $285.7(242.9-333.3)$ & 0.232 \\
\hline $\mathrm{PaO}_{2} / \mathrm{FIO}_{2}<250, \mathrm{n}(\%)$ & $21(37.5)$ & $665(28.0)$ & 0.118 \\
\hline
\end{tabular}

Abbreviations: IQR $=$ interquartile range; $\mathrm{SD}=$ standard deviation; $\mathrm{PaO}_{2} / \mathrm{FIO}_{2}=$ arterial oxygen tension to inspired oxygen fraction ratio; $\mathrm{PSI}=$ pneumonia severity index; $\mathrm{SatO}_{2}=$ oxygen saturation; $\mathrm{WBC}=$ white blood cells.

Percentages calculated on non-missing data.

Variables with $\mathrm{p}$-values $<0.05$ are in bold.

${ }^{a}$ Chi-square test, Fisher's exact test, Student's $t$-test or Mann-Whitney $U$ test, as appropriate. Median of C-RP values was used as cutoff value. 
Table 2 Severity and clinical outcomes of patients with $(n, 90)$ and without Non-CF Bronchiectasis $(n=3405)$.

\begin{tabular}{lccc}
\hline & $\begin{array}{c}\text { NCFBE-CAP } \\
(\mathrm{n}=90)\end{array}$ & $\begin{array}{l}\text { CAP } \\
(\mathrm{n}=3405)\end{array}$ & $1672(49.1)$ \\
\hline PSI classes IV-V, $\mathrm{n}(\%)$ & $50(55.6)$ & $524(19.4)$ & 0.227 \\
CURB-65 classes 3-5, $\mathrm{n}(\%)$ & $8(11.0)$ & $297(8.7)$ & 0.071 \\
Bacteraemia, $\mathrm{n}(\%)$ & $4(4.4)$ & $628(21.5)$ & 0.153 \\
Multilobar infiltration, $\mathrm{n}(\%)$ & $17(22.4)$ & $452(13.5)$ & 0.859 \\
Pleural effusion, $\mathrm{n}(\%)$ & $14(13.5)$ & $93(3.1)$ & 0.511 \\
ARDS criteria, $\mathrm{n}(\%)$ & $1(1.2)$ & & 0.336 \\
Site of care & & $551(16.2)$ & 0.055 \\
$\quad$ Outpatients & $7(7.8)$ & $2297(67.5)$ & 0.017 \\
Ward & $63(70.0)$ & $557(16.4)$ & 0.351 \\
$\quad$ ICU admission, $\mathrm{n}(\%)$ & $20(22.2)$ & $214(6.3)$ & 0.094 \\
Mechanical ventilation, $\mathrm{n}(\%)$ & $5(5.6)$ & $179(5.3)$ & 0.778 \\
Septic shock, $\mathrm{n}(\%)$ & $4(4.4)$ & $793(24.0)$ & 0.708 \\
Acute renal failure, $\mathrm{n}(\%)$ & $19(21.1)$ & $6.0(3.0-10.0)$ & 0.527 \\
Length of hospital stay (days), median (IQR) & $7.0(5.0-9.5)$ & $246(7.2)$ & 0.158 \\
30-day mortality, $\mathrm{n}(\%)$ & $4(4.4)$ & 0.312 \\
\hline
\end{tabular}

Abbreviations: ARDS = acute respiratory distress syndrome; CURB-65 = confusion, blood-urea nitrogen, respiratory rate, blood pressure, age; ICU = intensive care unit; IQR = interquartile range.

Percentages calculated on non-missing data.

Variables with $\mathrm{p}$-values $<0.05$ are in bold.

a Chi-square test, Fisher's exact test or Mann-Whitney $U$ test, as appropriate.

However, we performed multivariate analyses for ICU admission, prolonged LOS ( $>7$ days, median LOS of overall population) and 30-day mortality, but none of them showed NCFBE to be an independent associated factor, even after adjustments for NCFBE and potential confounding factors such as previous comorbidities, vaccinations, smoking habits, alcohol consumption and age (online supplement, Tables 2b,3b,4b).

Table 3 Distribution of the causative microorganisms in patients with a defined pneumonia aetiology $(n=1444)$.

\begin{tabular}{|c|c|c|c|}
\hline Microorganism & $\begin{array}{l}\text { NCFBE-CAP } \\
(\mathrm{n}=45)\end{array}$ & $\begin{array}{l}\text { CAP } \\
(n=1399)\end{array}$ & $\mathrm{p}$-Value \\
\hline Streptococcus pneumoniae & $20(44.4)$ & $598(42.7)$ & 0.821 \\
\hline Respiratory virus & $4(8.9)$ & $206(14.7)$ & 0.274 \\
\hline Mixed & $8(17.8)$ & $180(12.9)$ & 0.335 \\
\hline Atypical bacteria & $2(4.4)$ & $115(8.2)$ & 0.576 \\
\hline Mycoplasma pneumoniae & $1(2.2)$ & 54 (3.9) & 1.000 \\
\hline Chlamydophila pneumoniae & $1(2.2)$ & $39(2.8)$ & 1.000 \\
\hline Coxiella burnetii & $0(0)$ & $22(1.6)$ & 1.000 \\
\hline Legionella pneumophila & $1(2.2)$ & $100(7.1)$ & 0.163 \\
\hline Pseudomona aeruginosa ${ }^{\mathrm{b}}$ & $1(2.2)$ & $26(1.9)$ & 0.578 \\
\hline \multicolumn{4}{|l|}{ Enterobacteriaceae } \\
\hline Escherichia coli & $2(4.4)$ & $123(0.9)$ & 0.068 \\
\hline Klebsiella pneumoniae & $0(0)$ & $6(0.4)$ & 0.827 \\
\hline Proteus mirabilis & $0(0)$ & $1(0.1)$ & 0.969 \\
\hline Providencia stuartii & $0(0)$ & $1(0.1)$ & 1.000 \\
\hline Haemophilus influenzae & $2(4.4)$ & $43(3.1)$ & 0.413 \\
\hline Moraxella catarrhalis & $0(0)$ & $5(0.4)$ & 0.853 \\
\hline Haemophilus parainfluenzae & $0(0)$ & $1(0.1)$ & 0.969 \\
\hline Staphylococcus aureus & $3(6.7)$ & $28(2.0)$ & 0.069 \\
\hline Others Streptococcus species & $2(4.4)$ & $16(1.0)$ & 0.106 \\
\hline Streptococcus constellatus & $1(2.2)$ & $2(0.1)$ & 0.091 \\
\hline Streptococcus viridans & $1(2.2)$ & $9(0.6)$ & 0.272 \\
\hline Streptococcus pyogenes & $0(0)$ & $5(0.4)$ & 1.000 \\
\hline Others & $0(0.0)$ & $61(4.4)$ & 0.139 \\
\hline
\end{tabular}

Data are expressed as $\mathrm{n}(\%)$.

a Chi-square test or Fisher's exact test, as appropriate.

b $P$. aeruginosa when isolated alone. 
Table 4 Overall frequencies of main isolated microorganisms (monomicrobial and mixed infections).

\begin{tabular}{|c|c|c|c|c|c|}
\hline \multirow[b]{2}{*}{ Streptococcus pneumoniae } & \multicolumn{2}{|c|}{$\begin{array}{l}\text { NCFBE-CAP } \\
n, \%\end{array}$} & \multicolumn{2}{|l|}{$\begin{array}{l}\text { CAP } \\
n, \%\end{array}$} & \multirow{2}{*}{$\begin{array}{r}\text { p-value } \\
0.885\end{array}$} \\
\hline & 24 & $53.3 \%$ & 714 & $51.0 \%$ & \\
\hline Pseudomonas aeruginosa & 7 & $15.5 \%$ & 40 & $2.9 \%$ & $<0.001$ \\
\hline Haemophilus influenzae & 4 & $8.8 \%$ & 83 & $5.9 \%$ & 0.618 \\
\hline Respiratory viruses & 6 & $13.3 \%$ & 290 & $20.7 \%$ & 0.308 \\
\hline Atypical pathogens & 2 & $4.4 \%$ & 149 & $10.7 \%$ & 0.279 \\
\hline Enterobacteriaceae & 4 & $8.8 \%$ & 33 & $2.4 \%$ & 0.025 \\
\hline Staphylococcus aureus & 4 & $8.8 \%$ & 50 & $3.6 \%$ & 0.157 \\
\hline Legionella pneumophila & 1 & $2.2 \%$ & 111 & $7.9 \%$ & 0.266 \\
\hline
\end{tabular}

Note: Percentages refer to cases with known microbial etiology (NCFBE-CAP: 45, CAP: 1399).

Atypical pathogens include: Mycoplasma pneumoniae, Coxiella burnetii, Chlamydia pneumoniae.

Enterobacteriaceae include: Escherichia coli, Klebsiella pneumoniae, Proteus mirabilis, Providencia stuartii.

Variables with $\mathrm{p}$-values $<0.05$ are in bold.

\section{Discussion}

The main findings of this study were the following:

- Despite an older age and more comorbidities, NCFBE patients showed a similar clinical presentation at admission and similar severity scores (PSI, CURB-65).

- Moreover NCFBE patients also showed similar outcomes (mortality, MV, LOS, etc.) in comparison to the general CAP population.

- The microbiological investigation showed that S. pneumoniae was the most frequent isolate in both groups, but in the NCFBE-CAP patients there was an overall (monomicrobial and polymicrobial infections) increased rate of $P$. aeruginosa and Enterobacteriaceae compared to CAP.

- The NCFBE-CAP group showed a lower rate of adequate empiric antibiotic therapy according to guidelines ${ }^{18}$ in comparison with CAP.

This is the first study in the literature analyzing a large CAP series to investigate demographics, clinical characteristics and microbial etiology of pneumonia in NCFBE patients. This study clearly shows that NCFBE-CAP patients in Spain differ from the general CAP population in different aspects. In particular, NCFBE-CAP patients showed older age, more comorbidities and, consequently, increased vaccination rates (pneumococcal and influenza) and more inhaled (ICs) and systemic corticosteroids and previous antibiotic use than CAP population.

Our NCFBE-CAP population, did not show worse clinical outcomes (mortality, LOS etc.) in comparison with CAP albeit older age and more comorbidities. Therefore, it is questionable whether previous antibiotics, steroids and vaccinations could play a protective role in modulating pneumonia severity or whether the usual heterogeneity of NCFBE etiology and severity could also influence overall clinical presentation of pneumonia. Nevertheless it is important to consider that patients with an underlying chronic disease (respiratory or not) might seek health care earlier and with milder infections than previously healthy patients that might prefer home care or attend a hospital on a later stage. Indeed, there are limited studies in the literature describing outcomes for hospitalized NCFBE patients: in 2 studies on ICU patients the reported mortality rates were $40-60 \%$ at $1-4$ yrs but no specific data are reported about the role of CAP in these patients ${ }^{22,23}$; on the other hand Seitz et al. ${ }^{24}$ described an in-hospital mortality rate of $4.6 \%$ for NCFBE hospitalizations recorded in USA between 1993 and 2006, being pneumonia and influenza the main cause of death $(31 \%)$.

Interestingly, despite a greater prevalence of ICs among our NCFBE-CAP patients, their use did not show any association with main outcomes (mortality, LOS, etc.), but only with the risk of hospitalization (not ICU). However, both ICs and systemic steroids have demonstrated some protective role in general CAP by reducing its severity and the frequency of complications. ${ }^{25-33}$ Chronic ICs are largely used in NCFBE patients but their role in infections (exacerbations, pneumonia and chronic infections) should be surely further investigated.

The microbiological investigation showed that the majority of NCFBE-CAP are properly covered by current antimicrobial recommendations (CAP guidelines) but a greater prevalence of $P$. aeruginosa and Enterobacteriaceae was described in this population. These findings show that microbiological investigation is particularly important in NCFBE patients with pneumonia independently of initial severity to reduce the risk of treatment failure but surely more investigation is needed for the future to provide specific recommendations for clinical management of acute infections in NCFBE. In fact, accordingly to the literature, it is likely that in an NCFBE cohort (and not a CAP cohort) the prevalence of $P$. aeruginosa could be even higher and influence outcomes more consistently, as it has been demonstrated for chronic $P$. aeruginosa infection on lung function, exacerbations and mortality of NCFBE (ref), but the prognostic role of this pathogen in acute infections has to be better defined yet.

Concordantly, the lower proportion of adequate therapy in NCFBE-CAP (compared to CAP) and the increased rate of empiric antibiotic therapy directed at covering potential MDR pathogens could be possibly interpreted on the base of reported risk of $P$. aeruginosa and MDR pathogens in this population $^{6,11,12}$ and because of the lack specific recommendations for NCFBE. Nonetheless, mortality rates were similar in both groups indicating that no significant 
consequences were reported in our NCFBE population likely due to prompt antibiotic changes when needed.

Different guidelines for CAP and low respiratory tract infections $^{13,14,34}$ describe a number of risk factors for $P$. aeruginosa infection (tobacco, alcohol, malnutrition, recent hospitalization, frequent hospitalization, frequent or recent use of antibiotics, $\mathrm{FEV} \%<30 \%$, oral steroids) but no specific information is provided for NCFBE patients that are considered themselves at risk for this infection ${ }^{34}$ independently of their huge etiological and clinical heterogeneity. Only the series of 155 NCFBE patients from Mc Donnell et al. showed that low $\mathrm{FEV}_{1} \%$ and polymicrobial colonization are associated conditions with $P$. aeruginosa infection and that it occurs across all strata of lung function impairment. ${ }^{35}$ Arancibia et al. showed that the main risk factors for $P$. aeruginosa in CAP where pulmonary comorbidities (OR: 5.8 ) and a previous hospital admission (OR: 3.8) but no specific mention is given for NCFBE. ${ }^{36}$ Unfortunately no other data are currently available in the literature about risk factors for $P$. aeruginosa in NCFBE and particularly in CAP. For all these reasons further investigation is surely needed in NCFBE in order 1) to assess specific risk factors for $P$. aeruginosa and worse outcomes, 2) to guide antimicrobial therapy in both pneumonia and exacerbations.

Potential limitations of this study are: only one center was involved in the study which may not be representative of other regions, particularly considering the varied geographical distribution of NCFBE prevalence around the world; this is a retrospective analysis of a prospective data collection of CAP cases that was not primarily designed to investigate NCFBE therefore we are probably underestimating NCFBE prevalence since CT scan is usually not performed in all CAP patients. Moreover, the observational nature of this work intrinsically implies the risk of some risk of selection bias of the patients described in the study (such as the presence of comorbidities and related treatments, the ease of access to health facilities, local healthcare organization, etc.). Similarly, since our database was initially designed for CAP, HCAP cases are not included in our analysis with the exception of haemodialysis (when immunocompetent) and nursing home patients, that in our country have been demonstrated to have similar etiology to CAP. ${ }^{37}$ In particular patients with previous hospitalizations were considered affected by nosocomial infections and therefore excluded, while unfortunately the variables "home infusion therapy", "wound care" and "contact with a family member with known MDR pathogen" were not recorded in our database.

In summary:

- The NCFBE-CAP patients from our population were older and had more comorbidities but showed similar presentation and similar outcomes compared to the general CAP population; nevertheless an extrapolation of these results to the general NCFBE patients cannot be done without the support of further longitudinal studies based on NCFBE cohorts.

- The microbial etiology of NCBE-CAP was similar to CAP, $S$. pneumoniae being the most frequent isolate; nonetheless bronchiectatic patients showed more $P$. aeruginosa and Enterobacteriaceae than CAP.
- Consequently, we suggest a wide microbiological investigation should be always performed in NCFBE-CAP independently of initial severity, in order to reduce the risk of treatment failure and to avoid overuse of broad-spectrum antibiotics.

- Pneumococcal vaccination should be widely recommended in bronchiectatic patients considering the prevalence of this microorganism in CAP and chronic bronchial infection.

\section{Acknowledgments and funding}

Financial support: This work was supported by FIS PI080240, FIS PI080472, Ciberes (CB06/06/0028), Ciberes es una initiatives del ISCIII, 2009SGR911, IDIBAPS.

\section{Appendix A. Supplementary data}

Supplementary data related to this article can be found online at http://dx.doi.org/10.1016/j.jinf.2015.03.009.

\section{References}

1. Vendrell M, de Gracia J, Olveira C, Martínez MA, Girón R, Máiz L, et al. Diagnosis and treatment of bronchiectasis. Spanish Society of Pneumology and Thoracic Surgery. Arch Bronconeumol 2008 Nov;44(11):629-40.

2. Pasteur MC, Bilton D, Hill AT. British Thoracic Society guideline for non-CF bronchiectasis. Thorax 2010 Jul;65(Suppl. 1):i1-58.

3. Department of Health. NHLBI.UK, 2003-2004. Hospital episode statistics 2002-2003. 2012.

4. Weycker D, Edelsberg J, Oster G, Tino G. Prevalence and economic burden of bronchiectasis. Clin Pulm Med 2005;12(4): 205-9.

5. Twiss J, Metcalfe R, Edwards E, Byrnes C. New Zealand national incidence of bronchiectasis "too high" for a developed country. Arch Dis Child 2005 Jul;90(7):737-40.

6. Nicotra M, River M, Dale A. Clinical, pathophysiologic and microbiologic characterization of bronchiectasis in an aging cohort. Chest 1995;108:955-61.

7. King PT, Holdsworth SR, Freezer NJ, Villanueva E, Holmes PW. Characterisation of the onset and presenting clinical features of adult bronchiectasis. Respir Med 2006 Dec;100(12):2183-9.

8. Habesoglu MA, Ugurlu AO, Eyuboglu FO. Clinical, radiologic, and functional evaluation of 304 patients with bronchiectasis. Ann Thorac Med 2011 Jul;6(3):131-6.

9. Saynajakangas O, Keistinen T. A bronchiectatic patient's risk of pneumonia and prognosis. Cent Eur J Public Health 2009 Dec; $17(4): 203-6$.

10. Quinti I, Soresina A, Guerra A, Rondelli R, Spadaro G, Agostini C, et al. Effectiveness of immunoglobulin replacement therapy on clinical outcome in patients with primary antibody deficiencies: results from a multicenter prospective cohort study. J Clin Immunol 2011 Jun;31(3):315-22.

11. King PT, Holdsworth SR, Freezer NJ, Villanueva E, Holmes PW. Microbiologic follow-up study in adult bronchiectasis. Respir Med 2007 Aug;101(8):1633-8.

12. Angrill J, Agustí C, de Celis R, Rañó A, Gonzalez J, Solé T, et al. Bacterial colonization in patients with bronchiectasis: prevalence and comparison of diagnostic techniques. 159 ed. 1999. p. A559.

13. Torres A, Barberán J, Falguera M, Menéndez R, Molina J, Olaechea $P$, et al. Multidisciplinary guidelines for the 
management of community-acquired pneumonia. Med Clin (Barc) 2013 Mar 2;140(5):223.

14. Mandell LA, Wunderink RG, Anzueto A, Bartlett JG, Campbell GD, Dean NC, et al. Infectious Diseases Society of America/American Thoracic Society consensus guidelines on the management of community-acquired pneumonia in adults. Clin Infect Dis 2007 Mar 1;44(Suppl. 2):S27-72.

15. Smyth AR, Bell SC, Bojcin S, Bryon M, Duff A, Flume P, et al. European Cystic Fibrosis Society Standards of Care: best practice guidelines. J Cyst Fibros 2014 May;13(Suppl. 1):S23-42.

16. Pasteur MC, Helliwell SM, Houghton SJ, Webb SC, Foweraker JE, Coulden RA, et al. An investigation into causative factors in patients with bronchiectasis. Am J Respir Crit Care Med 2000;162:1277-84.

17. Cillóniz C, Ewig S, Polverino E, Marcos MA, Esquinas C, Gabarrús A, et al. Microbial aetiology of community-acquired pneumonia and its relation to severity. Thorax 2011 Apr; 66(4):340-6.

18. Menendez R, Torres A, Aspa J, Capelastegui A, Prat C, Rodriguez de CF. Community acquired pneumonia. New guidelines of the Spanish Society of Chest Diseases and Thoracic Surgery (SEPAR). Arch Bronconeumol 2010 Oct;46(10):543-58.

19. Roson B, Carratala J, Fernandez-Sabe N, Tubau F, Manresa F, Gudiol F. Causes and factors associated with early failure in hospitalized patients with community-acquired pneumonia. Arch Intern Med 2004 Mar 8;164:502-8.

20. Bodí M, Rodríguez A, Solé-Violán J, Gilavert MC, Garnacho J, Blanquer J, et al. Antibiotic prescription for communityacquired pneumonia in the intensive care unit: impact of adherence to Infectious Diseases Society of America guidelines on survival. Clin Infect Dis 2005 Dec 15;41(12):1709-16.

21. Hosmer D, Lemeshow S. Applied logistic regression. New York: Wiley; 1989.

22. Dupont M, Gacouin A, Lena H, Lavoué S, Brinchault G, Delaval P, et al. Survival of patients with bronchiectasis after the first ICU stay for respiratory failure. Chest 2004 May; 125(5):1815-20.

23. Alzeer AH, Masood M, Basha SJ, Shaik SA. Survival of bronchiectatic patients with respiratory failure in ICU. BMC Pulm Med 2007;7:17.

24. Seitz AE, Olivier KN, Steiner CA, Montes de OR, Holland SM, Prevots DR. Trends and burden of bronchiectasis-associated hospitalizations in the United States, 1993-2006. Chest 2010 Oct;138(4):944-9.

25. Polverino E, Cillóniz C, Dambrava P, Gabarrús A, Ferrer M, Agustí C, et al. Systemic corticosteroids for communityacquired pneumonia: reasons for use and lack of benefit on outcome. Respirology 2013 Feb;18(2):263-71.

26. Malo de Molina R, Mortensen EM, Restrepo MI, Copeland LA, Pugh MJ, Anzueto A. Inhaled corticosteroid use is associated with lower mortality for subjects with COPD and hospitalised with pneumonia. Eur Respir J 2010 Oct;36(4):751-7.
27. Chen D, Restrepo MI, Fine MJ, Pugh MJ, Anzueto A, Metersky ML, et al. Observational study of inhaled corticosteroids on outcomes for COPD patients with pneumonia. Am J Respir Crit Care Med 2011 Aug 1;184(3):312-6.

28. Ferrer M, Torres A, Martínez R, Ramírez P, Polverino E, Montull B. Inhaled corticosteroids and systemic inflammatory response in community-acquired pneumonia: a prospective clinical study. Respirology 2014 Aug;19(6):929-35.

29. Sellares J, López-Giraldo A, Lucena C, Cilloniz C, Amaro R, Polverino $\mathrm{E}$, et al. Influence of previous use of inhaled corticoids on the development of pleural effusion in communityacquired pneumonia. Am J Respir Crit Care Med 2013 Jun 1; 187(11):1241-8.

30. Krüger S, Ewig S, Kunde J, Hartmann O, Marre R, Suttorp N, et al. Assessment of inflammatory markers in patients with community-acquired pneumonia-influence of antimicrobial pre-treatment: results from the German competence network CAPNETZ. Clin Chim Acta 2010 Dec 14;411(23-24): 1929-34.

31. Ruiz M, Ewig S, Torres A, Arancibia F, Marco F, Mensa J, et al. Severe community-acquired pneumonia. Risk factors and follow-up epidemiology. Am J Respir Crit Care Med 1999 Sep; 160:923-9.

32. Schaaf B, Kruse J, Rupp J, Reinert RR, Droemann D, Zabel P, et al. Sepsis severity predicts outcome in communityacquired pneumococcal pneumonia. Eur Respir J 2007 Sep; 30(3):517-24.

33. Torres A, Sibila O, Ferrer M, Polverino E, Menendez R, Mensa J, et al. Effect of corticosteroids on treatment failure among hospitalized patients with severe community-acquired pneumonia and high inflammatory response: a randomized clinical trial. 15 A.D.

34. Niederman MS, Mandell LA, Anzueto A, Bass JB, Broughton WA, Campbell GD, et al. Guidelines for the management of adults with community-acquired pneumonia. Diagnosis, assessment of severity, antimicrobial therapy, and prevention. Am J Respir Crit Care Med 2001 Jun;163:1730-54.

35. McDonnell MJ, Jary HR, Perry A, MacFarlane JG, Hester KL, Small T, et al. Non cystic fibrosis bronchiectasis: a longitudinal retrospective observational cohort study of Pseudomonas persistence and resistance. Respir Med 2014 Aug 29. http: //dx.doi.org/10.1016/j.rmed.2014.07.021. pii: S09546111(14)00284-4. [Epub ahead of print].

36. Arancibia F, Bauer TT, Ewig S, Mensa J, Gonzalez J, Niederman MS, et al. Community-acquired pneumonia due to gram-negative bacteria and pseudomonas aeruginosa: incidence, risk, and prognosis. Arch Intern Med 2002 Sep 9; 162(16):1849-58.

37. Polverino E, Dambrava P, Cillóniz C, Balasso V, Marcos MA, Esquinas $C$, et al. Nursing home-acquired pneumonia: a 10 year single-centre experience. Thorax 2010 Apr;65(4): $354-9$. 